\title{
The Benefit of Early Trabeculectomy Versus Conventional Management in Primary Open Angle Glaucoma Relative to Severity of Disease
}

\author{
JEFFREY L. JAY and DONALD ALLAN \\ Glasgow
}

\begin{abstract}
Summary
One hundred and sixteen patients with newly diagnosed primary open angle glaucoma were selected for a randomised, prospective, multicentre trial if the untreated intraocular pressure was over $25 \mathrm{mmHg}$ and there was field loss characteristic of glaucoma. Conventional management of medical therapy followed by trabeculectomy in unsuccessful cases was compared with trabeculectomy at diagnosis followed where necessary by supplementary medical therapy. At a mean follow-up of 4.6 years there was no significant difference in visual acuity between the groups but the conventional management group had significantly greater loss of visual field which occurred during the unsuccessful attempt at medical control. The eyes which lost most visual field were those with least field loss at diagnosis and this paradox was attributed to a prolonged attempt at medical control in these eyes because they were thought to have a lower risk of visual field deterioration.
\end{abstract}

The initial results of this trial of early trabeculectomy in primary open angle glaucoma have been reported previously. ${ }^{1,2}$ Trabeculectomy was carried out at diagnosis without an attempt at medical control and compared with conventional management of medical treatment followed by trabeculectomy only where medical control failed.

At an average follow-up of 2.6 years early operation showed significantly better outcome for visual field by avoiding the deterioration which occurred during the attempt at medical control in the conventional management group. The observed difference in visual field could not be explained by changes in miotic therapy. There was no significant difference in visual acuity between the groups and the incidence of cataract was similar. The study has also confirmed the lower intraocular pressure achieved by trabeculectomy compared with medical therapy but the pressure achieved by operation was similar whether the operation was performed at diagnosis or only after failed medical therapy. The life expectancy of these glaucoma patients was found to be similar to that for the local population.

Further information is now available at average follow-up of 4.6 years and an attempt is made to estimate the severity of disease at which early trabeculectomy is justified.

\section{Patients and Methods}

The detailed protocol of this randomised, prospective, multicentre trial of the management of primary open angle glaucoma was fully described in a previous report. ${ }^{2}$ Newly diagnosed patients were included if the untreated 
intraocular pressure was greater than $25 \mathrm{~mm} \mathrm{Hg}$ on two occasions and there were visual field defects characteristic of glaucoma. Patients were allocated at random to one of two groups. Group A received medical treatment up to a maximum of three different drugs, followed in unsuccessful cases by trabeculectomy. Group B had trabeculectomy as soon as practicable after diagnosis but preliminary medical therapy was used where required to reduce the intraocular pressure to a safe level prior to operation. In both groups post-operative medical therapy was introduced when indicated according to the usual clinical criteria. On admission to the trial and at yearly intervals thereafter the patients were examined by the author and visual acuity and intraocular pressure were recorded with other relevant clinical information. At each of these visits the visual fields were examined with a Tübingen perimeter. The visual field was graded in five categories ranging from mild relative defects more than $10^{\circ}$ from fixation to absolute loss within the central $5^{\circ}$ in all quadrants (Table I). Intermediate examinations were performed at appropriate intervals by the referring ophthalmologists. They made their own decisions about management based on their own findings supported by the annual information from the trial investigator who gave no advice about change of treatment.

Where both eyes of a patient were available for study, one was selected at random for analysis of results. Changes in visual field sufficient to cause progression from one stage of the classification to another were used for comparison of the visual field performance of

Table I Five-stage classification of visual field changes

\begin{tabular}{cl}
\hline Stage & Visual field loss \\
\hline 1. & $\begin{array}{l}\text { Early relative defects (to } 1.0 / 10 \text { asb } \\
\text { Tübingen; equivalent to I-2e Goldmann) } \\
\text { in arcuate area or nasal step } \\
\text { Absolute defects (to } 1.0 / 00 \text { asb } \\
\text { Tübingen; equivalent to I-4e Goldmann) } \\
\text { outside } 10^{\circ} \text { from fixation in all quadrants } \\
\text { 2. }\end{array}$ \\
As Stage 2 but encroaching between $5^{\circ}$ \\
and $10^{\circ}$ from fixation in 1 to 4 quadrants \\
As Stage 2 but within $5^{\circ}$ of fixation in 1 \\
to 3 quadrants \\
As Stage 2 but within $5^{\circ}$ of fixation in all \\
quadrants
\end{tabular}

each group. Scatter diagrams were constructed for visual acuity and visual field to show change from diagnosis to final followup. The average field stage for each group was calculated at each year of follow-up and plotted to show the change in visual field with time. Analysis of the visual field change during each year was performed using an arbitrary scoring system where improvement in field of one stage or more for that year was awarded +1 and corresponding loss -1 . Changes in field judged to be significant but not reaching the next stage boundary were awarded \pm 0.5 . Kaplan-Meier experimental survival curves (life tables) for visual fields were drawn to compare sub-groups of $A$ and $\mathrm{B}$ according to severity of visual field loss at diagnosis. Comparisons were made between group A eyes which had not required operation, group A eyes which had required operation and group $\mathrm{B}$.

Statistical analysis was performed by ' $t$ '; $\mathrm{x}^{2}$; Mann-Whitney and log rank tests as appropriate.

\section{Results}

One hundred and sixteen patients were allocated to the trial between 1980 and 1985 . Four refused early operation and were excluded. Maximum follow-up is now seven years (mean 4.6 years). The number available for analysis at each year is indicated in Table II, together with the number dead or lost to follow-up.

Figure 1 shows the change in corrected visual acuity from diagnosis to latest follow-up in each group, the group A data include eyes eventually requiring operation. Within each group the numbers showing reduced visual acuity are significantly greater than those with the same or improved acuity $(0.02<\mathrm{p}<0.05$; $\left.\mathrm{x}^{2}\right)$ but there is no significant difference in final acuity between the groups ( $p=0.44$; MannWhitney). There was however a difference in final acuity between group A eyes which required operation because of failed medical control and group A eyes which were successfully controlled without operation. These two sub-groups had no significant difference in initial acuity ( $\mathrm{p}=0.072$; Mann-Whitney) but those who eventually required operation had poorer acuity at final follow-up ( $\mathrm{p}=$ 0.007; Mann-Whitney). This difference arose 
Table II Patients available for study at end of each year including numbers dead or lost to follow-up

\begin{tabular}{|c|c|c|c|c|c|}
\hline \multirow{2}{*}{$\begin{array}{l}\text { At end } \\
\text { of year }\end{array}$} & \multicolumn{3}{|c|}{ No. available for study } & \multirow[b]{2}{*}{ No. dead } & \multirow{2}{*}{$\begin{array}{l}\text { No. lost to } \\
\text { follow-up }\end{array}$} \\
\hline & $A$ & $B$ & Total & & \\
\hline 1. & 57 & 50 & 107 & 5 & 0 \\
\hline 2. & 53 & 48 & 101 & 10 & 1 \\
\hline 3. & 50 & 46 & 96 & 13 & 2 \\
\hline 4. & 39 & 44 & 83 & 15 & 3 \\
\hline 5. & 25 & 30 & 55 & 16 & 3 \\
\hline 6. & 18 & 18 & 36 & 12 & 2 \\
\hline 7. & 9 & 6 & 15 & 6 & 3 \\
\hline
\end{tabular}

because of progressive field loss involving central fixation.

Similar displays for visual field change by each stage of the classification (Fig. 2) demonstrate significantly increased visual field loss with conventional management in group A compared with early trabeculectomy in group $\mathrm{B}$ ( $\mathrm{p}=0.027$; Mann-Whitney). Figure 3 compares the change in the group average visual field stage with time. Group A deteriorates in the first and second years so that the mean visual field is significantly worse than group B at two and three years (year $2=$ $0.02<\mathrm{p}<0.05$, year $3=0.01<\mathrm{p}<0.02$; MannWhitney). Group A then stabilises at a level below group $\mathrm{B}$ which has remained at the pretreatment level or better.

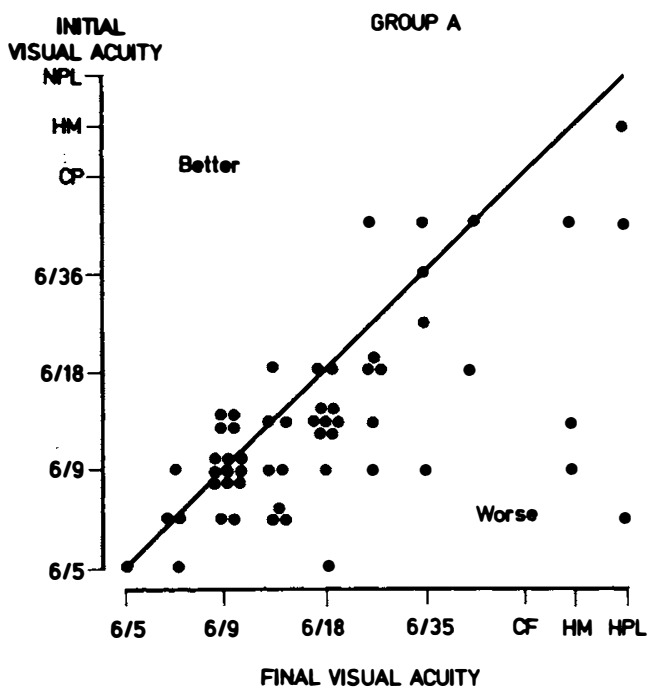

The change in visual field in each group during the course of each individual year using the arbitrary scoring system is shown in Table III. There is statistically significant deterioration of field in group A compared with group $B$ in the first year with less marked relative deterioration in the second year and none in succeeding years.

The groups were then stratified according to severity of disease at diagnosis. Eyes with stage 1 field loss at diagnosis had significantly lower intraocular pressures than those with more advanced field loss but for field loss of stage 2 or more there was no further detectable increase in intraocular pressure with increasing stage of field loss (Table IV). The initial intraocular pressure could not, how- 
GROUP A

\section{INTTAL}

USUAL FED

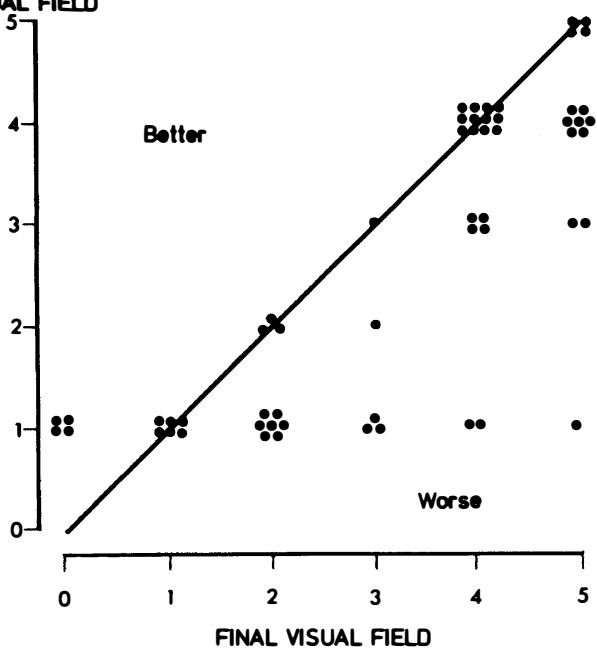

GROUP B

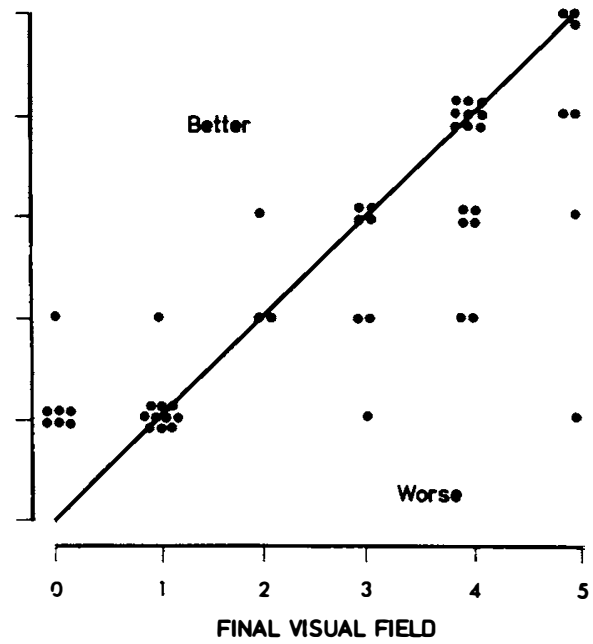

Fig. 2. Change in visualfield stage from diagnosis to latest follow-up (mean = 4.6 years). Group A, conventional management, shows significantly greater loss of field compared with group B, early trabeculectomy $(p=0.027$; Mann-Whitney).

ever, be used to predict failure of medical control in group A either as a whole or stratified by field stage at diagnosis (Table V).

The difference in outcome for visual field was found to be related to the severity of field loss at diagnosis. The Kaplan-Meier curves for survival of visual field within the same stage of the visual field classification as at diagnosis are shown in Figures 4 and 5. For both group $\mathrm{A}$ and $\mathrm{B}$, eyes in stage 1 of the field classification are considered separately from those in stages 2-4. Stage 5 eyes were excluded as there is no further stage to which they might move. It was found that the curves for those with more severe field loss at diagnosis (stage 2-4, figure 4) showed a small advantage for group $\mathrm{B}$, not statistically significant (overall, $0.1<\mathrm{p}<0.2$; year $1=0.2<\mathrm{p}<0.5$; year $2=$ $0.2<\mathrm{p}<0.5$; year $3=\mathrm{p}>0.5$; year $4=$ $0.2<\mathrm{p}<0.5$; year $6=\mathrm{p}>0.5$; log rank test). There was a much greater difference between the groups for those with mild (stage 1) field loss at diagnosis (Fig. 5). Approximately $90 \%$ of group B eyes in stage 1 at diagnosis remain in the same field stage three years later compared with only $60 \%$ of the same sub-group of group A. The curves for stage 1 eyes are sig- nificantly different (overall $\mathrm{p}<0.001$; year $1=$ $0.001<\mathrm{p}<0.01$; year $2=0.01<\mathrm{p}<0.02$; year 3 $=0.02<\mathrm{p}<0.05$; years 4 and $5=0.1<\mathrm{p}<0.2$; $\log$ rank test). Therefore the difference in outcome for visual fields between groups $\mathrm{A}$ and $\mathrm{B}$ arises mainly in the sub-group which has least visual field damage at diagnosis.

The frequency and timing of operation in group A was then examined. Figure 6 shows the Kaplan-Meier curves for the number of group A eyes surviving without operation at

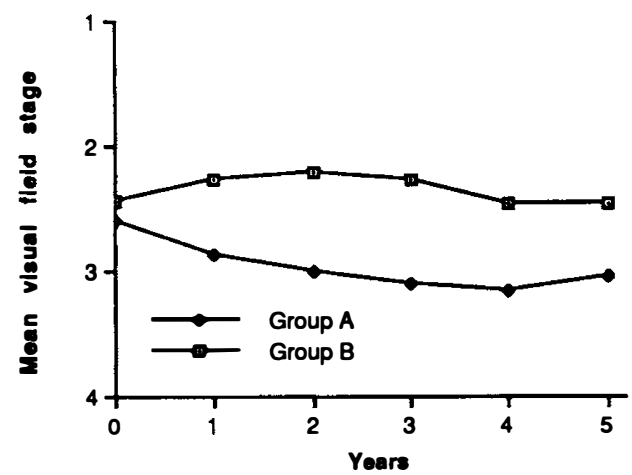

Fig. 3. Group mean visual field at each year of followup. Group $A$ appears to deteriorate relative to group $B$ in the first and second years and then runs parallel at $a$ reduced level of visual field. 
Table III Comparative scores for visual field change during each individual year for Groups ' $A$ ' and ' $B$ '. Group ' $A$ ' matches the performance of Group ' $B$ ' only after rapid deterioration in the first and second years

\begin{tabular}{|c|c|c|c|}
\hline \multirow[b]{2}{*}{ Year } & \multicolumn{2}{|c|}{$\begin{array}{l}\text { Change in visual field score } \\
\text { for each year }\end{array}$} & \multirow{2}{*}{$\begin{array}{c}\text { 'p' } \\
\text { (Mann-Whitney) }\end{array}$} \\
\hline & Group $A(n)$ & Group B (n) & \\
\hline 1 & $-13.5(57)$ & $+1 \quad(50)$ & 0.03 \\
\hline 2 & $-13.5(53)$ & $-3 \quad$ (48) & 0.06 \\
\hline 3 & $-2.5(50)$ & $-6 \quad(46)$ & 0.64 \\
\hline 4 & $-8 \quad(39)$ & $-5.5(44)$ & 0.74 \\
\hline 5 & $-2 \quad(25)$ & $-5 \quad(30)$ & 0.58 \\
\hline 6 & $-2 \quad(18)$ & (18) & 0.70 \\
\hline
\end{tabular}

each year. Separate curves for the whole group and for the sub-groups with stage 1 and stage 2-5 fields at diagnosis are shown. At three years trabeculectomy has been performed in $55 \%$ of the whole group (100 minus $\%$ of survivors in Figure 6 ) but in only $38 \%$ of stage 1 eyes compared with $70 \%$ of stage $2-5$ eyes. Throughout the follow-up period fewer operations have been performed on those with milder field loss at diagnosis $(p<0.001$, log rank test). There was also greater delay in operation in stage 1 eyes which had a mean time of operation at 22.9 months compared with 11.4 months for stage $2-5$ eyes (Table VI).

Figure 7 displays the visual field outcome according to whether or not the group A eyes eventually required operation. The eyes which were successfully controlled without operation performed no better than the group $\mathrm{B}$ eyes and were significantly worse $(0.02<\mathrm{p}<0.05, \log$ rank test $)$ at year 1 . The sub-group of $\mathrm{A}$ in which medical treatment had to be abandoned deteriorated until the end of the third year by which time most of the operations had been performed (see Figure $6)$. The log rank test applied to the data in Figure 7 indicated that the poorer performance of the group A eyes which had required operation is statistically significant $(\mathrm{p}<0.001)$.

\section{Discussion}

The results now available from this trial confirm that in established glaucoma the method of management makes an important difference to the prognosis. In ocular hypertension it is already known that successful lowering of intraocular pressure with adrenaline (Eppy) eye drops significantly reduces the risk of subsequent loss of visual field. ${ }^{2,3}$ In the latter study the benefit was more marked in the more severe cases, cup to disc ratio $>0.4$; intraocular pressure $>24 \mathrm{mmHg}$. Recently timolol eye drops have been shown to improve the prognosis in similar subjects. ${ }^{4}$ Operations to create a drainage fistula provide lower intraocular pressure than medical therapy ${ }^{2,6,7,8}$ and surgery is the most effective method of reducing diurnal variation in intraocular pressure. ${ }^{8}$ The present report quantifies the benefit of gaining this intraocular pressure advantage without a preliminary trial of medical therapy. If there is any bias in the study it will favour the conventional management group as the study patients probably had closer supervision and assessment of medical therapy than usual.

The strategy of early surgery did not compromise the visual acuity (Fig. 1) for although both groups showed reduction from the initial visual acuity the change was similar in the two groups. The incidence of progressive lens

Table IV Stage of visual field loss at diagnosis and initial intraocular pressure before treatment for Groups ' $A$ ' and ' $B$ ' combined

\begin{tabular}{ccc}
\hline ' $n$ ' & $\begin{array}{c}\text { Visual field stage } \\
\text { at diagnosis }\end{array}$ & $\begin{array}{c}\text { Mean IOP at } \\
\text { diagnosis (mm Hg) }\end{array}$ \\
\hline 41 & 1 & $32.23^{*}$ \\
12 & 2 & 40.50 \\
17 & 3 & 38.24 \\
30 & 4 & 37.54 \\
7 & 5 & 40.43 \\
\hline
\end{tabular}

* Significantly lower than other groups, by analysis of variance, $0.01<\mathrm{p}<0.05$ and by two-group analysis Stage 1 v. Stage $2-5, \mathrm{p}<0.001$. 
Table V Initial untreated intraocular pressure of Group 'A' eyes stratified by visual field at diagnosis and whether or not operation was eventually performed. For a given stage of field loss intraocular pressure is not a good predictor of whether medical treatment will be adequate

\begin{tabular}{lccc}
\hline & \multicolumn{2}{c}{ Mean IOP at diagnosis $(\mathrm{mmHg})$} & \\
\cline { 2 - 3 } Initial field loss $(n)$ & Controlled medically $(n)$ & Operated $(n)$ & ' $t$ ' test \\
\hline Stage 1 (23) & $29.62(13)$ & $33.60(10)$ & $\mathrm{p}=0.069$ (n.s.) \\
Stage 2-5 (34) & $36.10(10)$ & $39.96(24)$ & $\mathrm{p}=0.24$ (n.s.) \\
\hline
\end{tabular}

opacity has also been found to be similar in spite of the fact that group A had approximately half the number of drainage operations with a,shorter mean post-operative follow-up. ${ }^{2}$ Thus the risk of cataract cannot be related to the operation alone. When cataract did develop it was not usually in eyes noted to have lens opacities at the start of the study. Therefore a mild degree of cataract should not cause the surgeon either to delay trabeculectomy or combine a cataract extraction with the trabeculectomy unless the degree of lens opacity already justifies cataract surgery. The slightly poorer final visual acuity of the group A eyes which did eventually require trabeculectomy was more likely to be a result of the surgical delay comprising central fixation by loss of visual field than a result of cataract formation.

The clear advantages of early trabeculectomy for preservation of visual field (Fig. 2) occurs in the first two years (Fig. 3, Table III). Thereafter most of the group A eyes which cannot be controlled medically have been identified and submitted to operation (Fig. 6). After this delayed operation the stability of the visual field matches that of group B but the group A eyes remain at a permanent disadvantage (Figs. 3, 4, 5 \& 6). Similarly the intraocular pressure after delayed operation equals that achieved by early trabeculectomy. ${ }^{2}$ The main hazard is the attempt at medical control in those eyes where it will prove unsuccessful. Argon laser trabeculoplasty, although successful in lowering intraocular pressure in some cases, becomes less effective with time and also delays trabeculectomy. ${ }^{9}$

When the performance of the eyes in group A with mild field loss and generally lower pressures (Table IV) at diagnosis is compared with the eyes in the same group with more severe field loss, the eyes with less severe disease paradoxically perform worse than those with more severe disease (Figs. 4 \& 5). This may be attributd to the finding that there was later (Table VI) and less frequent operation (Fig. 6) in milder cases. In the more severe cases medical treatment was aban-

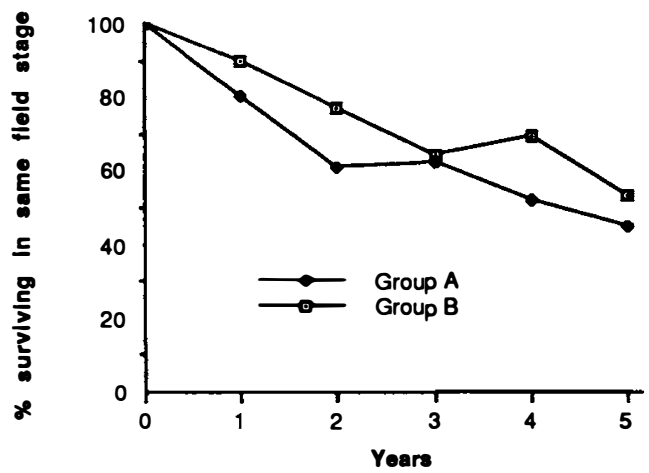

Fig. 4. Survival curves showing percentage of eyes remaining in the same stage of the visual field classification for those with more advanced field loss at diagnosis (stages 2-4). The groups are similar.

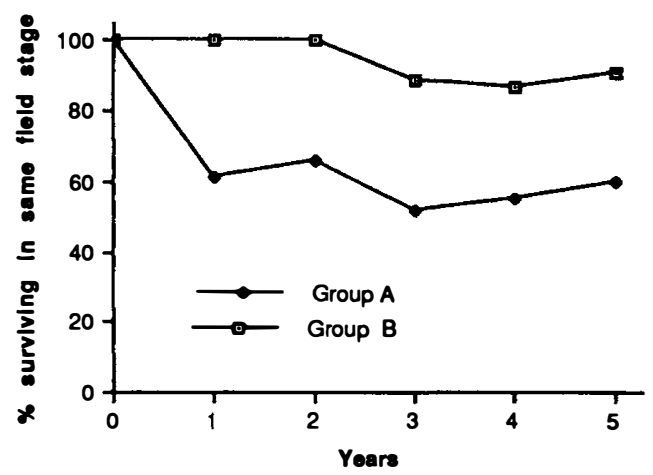

Fig. 5. Survival curves showing percentage of eyes remaining in the same stage of the visual field classification for those with mild field loss at diagnosis (stage 1). The marked benefit for group B is significant $(p<0.001$, log rank test). 


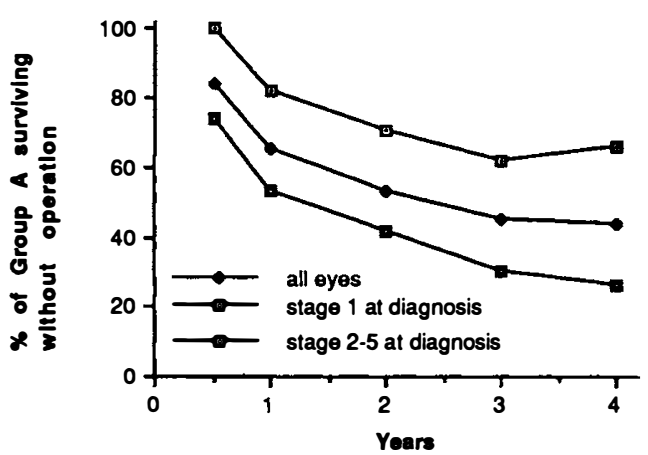

Fig. 6. Survival curves for percentage of eyes in group $A$ remaining without operation at each year. Separate curves for whole group data and sub groups according to severity of field loss at diagnosis. The operation rate slows after the third year.

doned quickly if the response was less than ideal but in mild cases a higher level of pressure on medical treatment was accepted until it was seen that the pressure was increasing or the visual field deteriorating. Even in those eyes maintained successfully on medical treatment there was a rather rapid fall in the visual field survival curve (Fig. 7) in the first year which might indicate that the time taken to find the ideal medical treatment was detrimental.

As yet it is impossible to predict which glaucoma patients will have progressive loss of visual field. ${ }^{10,11}$ Early trabeculectomy can now be seen to protect the visual field and we must decide at what severity of disease this strategy is justified. With untreated intraocular pressure of over $25 \mathrm{mmHg}$ and dense (1.0/00asb Tübingen; 1-4e Goldmann) scotomata, even of small area, $70 \%$ of eyes treated conventionally require operation within three years (Fig. 6). Except in special circumstances early trabeculectomy is indicated in these cases. In eyes with similar intraocular pressure but only mild field loss $(1.0 /$ 10asb Tübingen; 1-2e Goldmann) only $38 \%$ fail to be controlled medically at three years. It is therefore difficult to justify early operation for all patients in this category. Delay has however been shown to be a particular hazard in these milder cases and so the attempt at medical control should be brief and closely supervised so that trabeculectomy can be offered at the earliest suspicion of unsatisfactory intraocular pressure reduction, deterioration in visual field or poor compliance. Even in retrospect eyes which were controlled medically performed no better than those which had early surgery.

These results indicate the benefit of early trabeculectomy even in mild cases of established primary open angle glaucoma. Within the range of severity of disease in this study there is nothing to suggest that there is a level of visual field loss below which medical therapy is to be preferred. It would however be unsafe to extrapolate these findings to glaucomatous eyes with untreated intraocular pressure less than $26 \mathrm{mmHg}$ or to eyes with ocular hypertension.

Statistical significance has been achieved with a relatively small number of patients and using marked changes in visual field as criteria for analysis. The results therefore indicate an important clinical difference between the groups.

Table VI Mean delay before operation for failed medical control in Group ' $A$ ' related to visual field at diagnosis

$\left.\begin{array}{cc}\hline \text { Initial field loss } & \begin{array}{c}\text { Mean delay before } \\ \text { operation (months) }\end{array} \\ \hline \text { Stage } 1 & 22.9 \\ \text { Stage } 2-5 & 11.4\end{array}\right\} \mathrm{p}=0.047$

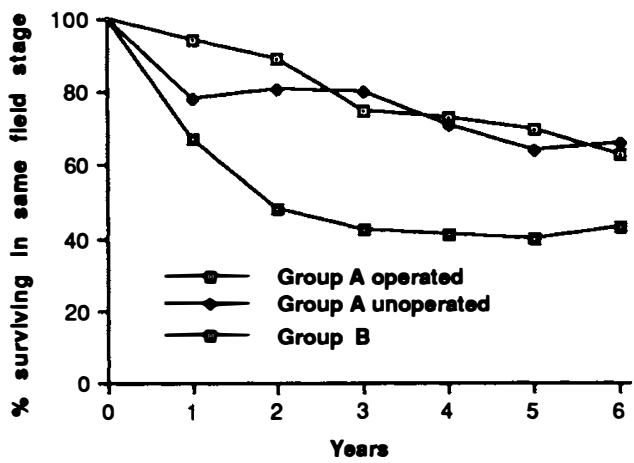

Fig. 7. Visual field survival curves showing percentage eyes remaining in the same stage of the classification for group A controlled without operation, group A not controlled without operation and group $B$. 
We are grateful to the following who contributed patients to this study: Dr. T. Barrie, Dr. J. S. Cant, Dr. J. Dudgeon, Professor W. S. Foulds, Professor J. V. Forrester, Dr. P. M. Kyle, Dr. M. LeMay, Dr. S. B. Murray.

\section{References}

1 Jay JL: Earlier trabeculectomy. Trans Ophthalmol Soc UK 1983, 103: 35-8.

2 Jay JL and Murray SB: Early trabeculectomy versus conventional management in primary open angle glaucoma. Br J Ophthalmol 1988, 72: 881-9.

${ }^{3}$ Becker B and Morton WR: Topical epinephrine in glaucoma suspects. Am J Ophthalmol 1966, 62: 272-7.

${ }^{4}$ Shin DH, Kolker AE, Kass MA, Kaback MB, Becker B: Long term epinephrine therapy of ocular hypertension. Arch Ophthalmol 1976, 94: 2059-60.

${ }^{5}$ Krug JH, Edelstein DJ, Remis LL, Hertzmerk E, Epstein DL: Long term study of timolol versus no treatment in the management of glaucoma suspects. Ophthalmology 1989, 95: (in press).

${ }^{6}$ Smith RJH: Medical versus surgical therapy in glaucoma simplex. Br J Ophthalmol 1972, 56: 277-83.

${ }^{7}$ Smith RJH: The enigma of primary open angle glaucoma. Trans Ophthalmol Soc UK 1986, 105: 618-33.

${ }^{8}$ Migdal $\mathrm{C}$ and Hitchings R: Control of chronic simple glaucoma with primary medical, surgical and laser treatment. Trans Ophthalmol Soc UK 1986, 105: 653-6.

${ }^{9}$ Gilbert CM, Brown RH, Lynch MG: The effect of argon laser trabeculoplasty on the rate of filtering surgery. Ophthalmology 1986, 93: 362-5.

${ }^{10}$ Armaly MF: Lessons to be learned from the collaborative glaucoma survey. Surv Ophthalmol 1980, 25: $139-44$.

${ }^{11}$ Richler M, Werner EB, Thomas D: Risk factors for progression of visual field defects in medically treated patients with glaucoma. Can J Ophthalmol 1982, 17: 245-8. 